\title{
Phenotypic and Genotypic Identification of Ticks Sampled from Wildlife Species in Selected Conservation Sites of Kenya
}

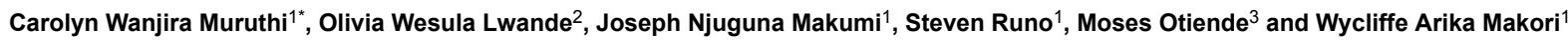 \\ ${ }^{1}$ Department of Biochemistry and Biotechnology, Kenyatta University, Kenya \\ ${ }^{2}$ Department of Clinical Microbiology, Virology, Umea University, Sweden \\ ${ }^{3}$ Forensic and Genetics Laboratory, Veterinary Services Department, Kenya Wildlife Service, Kenya
}

*Corresponding author: Carolyn Wanjira Muruthi, Department of Biochemistry and Biotechnology, Kenyatta University, P.O BOX $43844-00100$, Kenya, Tel: +254 790 466; E-mail: mwcarolyn@gmail.com

Rec date: Dec 14, 2015; Acc date: Jan 08, 2016; Pub date: Jan 11, 2016

Copyright: $\odot 2016$ Muruthi CW, et al. This is an open-access article distributed under the terms of the Creative Commons Attribution License, which permits unrestricted use, distribution, and reproduction in any medium, provided the original author and source are credited.

\begin{abstract}
Hard ticks are blood feeding ectoparasites that infest humans and animals and are vectors of pathogenic microorganism that cause severe infectious diseases. Morphological identification has been the main approach of identifying ticks but the technique is considered inaccurate and difficult. Molecular techniques have recently been considered to be appropriate approaches for accurate and rapid identification and Internal Transcribed Spacer 2 (ITS 2) has been shown to differentiate genus of hard ticks. Currently, genetic identification of ticks using ITS 2 has not been carried out in Kenya. In this study, 80 tick samples were collected from Lake Nakuru and Tsavo National Parks and were identified morphologically using appropriate identification keys. DNA was extracted from the appendages using DNA extraction kit followed by partial amplification of ITS 2 gene. The PCR products were then analyzed by gel electrophoresis and positive PCR products were sequenced. Of the tick samples four genera were identified morphologically; Amblyomma, Hyalomma, Rhipicephalus and Dermacentor. Of the tick samples identified and compared with the sequences in the GenBank, six and seven samples showed $98-100 \%$ homology with $A$. variegatum and $R$. pulchellus respectively and they clustered in their respective monophyletic group in the phylogeny tree with a bootstrap of $99 \%$. Two samples showed $92 \%$ homology with $\mathrm{H}$. dromedarii and the study sequences clustered with the reference sequence with a bootstrap of $99 \%$ while six samples showed $95 \%$ homology with $H$. marginatum rufipes, however, only four of these samples clustered together with the reference sequence in the phylogeny with a bootstrap of $95 \%$. One sample showed $91 \%$ homology with $A$. humerali and did not cluster together in the phylogeny tree. Congruency between both techniques was high with a correlation coefficient of 0.941. This is the first report of phenotypic and genotypic traits of tick species in Kenya and the findings will add value to the existing knowledge in identification of ticks.
\end{abstract}

Keywords: Ixodidae; ITS 2; Kenya

\section{Background}

Ticks are ubiquitous blood feeding ectoparasites of humans and animals and are vectors of a plethora of pathogens that cause severe infectious diseases in humans and livestock [1]. Tick infestation and the diseases they transmit result in huge economic losses in livestock production and continue to cripple the industry, especially in subSaharan Africa [2]. The diversity and number of wildlife species is enormous all over the world and this diversity sustain a large and diverse tick- borne vectors of pathogens $[3,4]$. Most wild herbivores, including buffaloes and elephants are believed to be significant reservoirs of tick-borne pathogens that affect humans and animals [5] as they support a large population of tick species [6].

Reliable and quick identification of ticks is therefore, important in the control of spread of tick-borne diseases. Morphological characterization based on phenotypic traits has been the traditional method of identifying ticks. Morphological identification method is further weakened by the fact that traits used to differentiate species tend to overlap between species or vary within species or according to age and size [7]. Additionally, morphological identification of physically damaged ticks due to poor handling and preservation is often inaccurate. The advent of molecular techniques and development of markers that can identify ticks have revolutionized our understanding of other insect vectors and may be useful in studies of tick taxonomy and diversity.

To comprehend the epidemiology of tick-borne pathogens and develop effective strategies for controlling the diseases, accurate identification of the vector is vital. Currently, the tick diversity in Kenya is based on historical records that were determined by morphological methods [8] and yet the method has inherent challenges and weakness that weaken accuracy of species identification. Although, ticks can be identified directly using genetics, it is important to describe its distinctive phenotypic features and test for congruency with genetic classification. Currently, genetic identification techniques have not been effectively used in identification of tick in Kenya. Still, there is no evidence that the phenotypic and genotypic traits of tick species in Kenya are congruent. Therefore, incongruency in identification based on the two techniques will justify the need for taxonomic re-classification. Additionally, the information generated will quicken future identification of tick species. As such, the purpose of this study is to genetically identify tick samples and confirm whether the distinctive phenotypic traits for tick species differentiation are congruent with genetic traits. 
Citation: Muruthi CW, Lwande OW, Makumi JN, Runo S, Otiende M, et al. (2016) Phenotypic and Genotypic Identification of Ticks Sampled from Wildlife Species in Selected Conservation Sites of Kenya. J Veterinar Sci Technol 7: 293. doi:10.4172/2157-7579.1000293

Page 2 of 8

\section{Methods}

\section{Ethics statement}

The ethics committee of the Kenya Wildlife Service (KWS) approved the study as it was based on opportunistic tick collection from immobilized elephants, buffaloes and rhinoceros during translocation, collaring and veterinary exercises in Lake Nakuru and Tsavo National Parks. KWS guidelines on Wildlife Veterinary Practice-2006 were followed and all KWS veterinarians follow the Veterinary Surgeons and Veterinary Para-Professionals Act 2011, Laws of Kenya, which regulates veterinary practices in Kenya.

\section{Tick collection}

A total number of 80 ticks were collected randomly during scheduled veterinary management activities within the Lake Nakuru and Tsavo National parks. The animals were immobilized by the Kenya Wildlife Service veterinarians using a combination of etorphine and xylazine (Norvatis, PTY, Ltd, South Africa). Ticks were pulled off manually from the animals by hands and with forceps and placed in sterile loosely capped plastic vials and transported to the laboratory in dry ice. In the laboratory the ticks were stored at $-80^{\circ} \mathrm{C}$

\section{Morphological identification of ticks}

Sampled ticks were kept at room temperature to thaw, and then washed twice with sterile water to remove excess particulate contamination from animal skin, rinsed once with $70 \%$ ethanol. They were mounted on slides and examined using a stereoscope microscope at a magnification of $\times 40, \times 80$, and $\times 100$. Identification of the ticks was by sex and species using appropriate identification keys [8]. The identified ticks were transferred to sterile vials, and stored at $-80^{\circ} \mathrm{C}$ until processing at the KWS Veterinary Laboratory, Nairobi.

\section{Molecular analyses of ticks}

DNA isolation and PCR: DNA was extracted from each sample using DNA extraction kit (DNeasy blood \& Tissue Kit, QIAGEN (Germany) following the manufacture's protocol. Genomic DNA extracted from the 28 ticks' tissues was amplified. Each species identified morphologically was represented by more than one sample. A pair of degenerate primers designed for ITS 2 amplification [9] were used; forward 5'-YTGCGARACTTGGTGTGAAT-3' and reverse 5' TATGCTTAARTTYAGSGGGT-3'.

Amplification of DNA was carried out in a final volume of $25 \mu \mathrm{l}$ containing $15.8 \mu \mathrm{l}$ of $\mathrm{dH} 20,2 \mu \mathrm{l}$ of the genomic DNA, $2 \mu \mathrm{l}$ of each primer (forward and reverse), $5 \mu \mathrm{l}$ PCR buffer, $0.2 \mu \mathrm{l}$ of Taq DNA polymerase. The tubes were then placed into a programmed Applied Biosystems Veriti 96 well thermocycler (Germany) where the reactions mixture was subjected to $2.5 \mathrm{~min}$ DNA denaturization at $94^{\circ} \mathrm{C}, 35$ cycles of denaturization at $94^{\circ} \mathrm{C}$ for $30 \mathrm{sec}$, annealing at $50^{\circ} \mathrm{C}$ for $1 \mathrm{~min}$ and elongation at $72^{\circ} \mathrm{C}$ for $1 \mathrm{~min}$. The reaction was completed by a further $30 \mathrm{~min}$ step at $72^{\circ} \mathrm{C}$. The procedure was repeated twice for each sample in order to yield a final volume of $50 \mu \mathrm{l}$.

\section{Electrophoresis and purification of PCR products}

The amplified products were analyzed by electrophoresis on $1 \%$ Agarose gel by aliqouting $4 \mu \mathrm{l}$ of PCR products and $1 \mathrm{~kb}$ DNA ladder and run on the gel stained with ethidium bromide for 1 hour at 80 volts. The PCR products were purified using QIAGEN PCR Purification Kit (Germany) following the manufacturer's protocol.

\section{Sequencing and analysis}

Purified DNA products were sent to Biosciences Eastern and Central Africa (BecA-ILRI) for sequencing. Sequencing was carried out through ABI310 DNA sequences. Sequences were taken through Bioedit, and aligned using multiple alignment program ClustalX. The default 6.66 and 15 values for gap extension and gap opening respectively were used. Misaligned nucleotides were detected and realigned manually. BLASTN searches were done in the GenBank so as to identify matches to the sample sequences.

\section{Congruency test}

Correlation statistic were computed to test for congruency between morphological and phenotypic traits at $\mathrm{P}=0.01$.

\section{Results}

\section{Morphological identification}

Tick species that were correctly identified morphologically by genus from Lake Nakuru and Tsavo National Parks from elephants, buffaloes and rhinoceros. Four genera were correctly identified namely Amblyomma, Hyalomma, Rhipicephalus and Dermacentor (Table 1). Some of tick species identified morphologically include; Hyalomma arbiparmatum, Amblyomma tholloni, Rhipicephalus pulchellus, Amblyomma gemma, Amblyomma variegatum, Hyalomma marginatum rufipes (Figures 1A, 1B, 1C, 1D, 1E and 1F).

\begin{tabular}{|l|l|l|l|l|}
\hline Name & Stage & Number & Host & Location \\
\hline Amblyomma gemma & Adult & 13 & (Loxondota Africana africana) Elephant & Tsavo National Park \\
\hline $\begin{array}{l}\text { Amblyomma } \\
\text { variegatum }\end{array}$ & Adult & 7 & $\begin{array}{l}\text { (Syncerus } \\
\text { caffer) Buffaloes }\end{array}$ & L. Nakuru National Park \\
\hline $\begin{array}{l}\text { Amblyomma } \\
\text { thollonia }\end{array}$ & Adult & 1 & (Loxondota Africana africana) Elephant & Tsavo National Park \\
\hline $\begin{array}{l}\text { Rhipicephallus } \\
\text { pulchellus }\end{array}$ & Adult & 24 & $\begin{array}{l}\text { (Loxondota } \\
\text { Africana }\end{array}$ & Tsavo National Park \\
\hline
\end{tabular}


Citation: Muruthi CW, Lwande OW, Makumi JN, Runo S, Otiende M, et al. (2016) Phenotypic and Genotypic Identification of Ticks Sampled from Wildlife Species in Selected Conservation Sites of Kenya. J Veterinar Sci Technol 7: 293. doi:10.4172/2157-7579.1000293

Page 3 of 8

\begin{tabular}{|l|l|l|l|l|}
\hline & & & $\begin{array}{l}\text { Africana) } \\
\text { Elephant }\end{array}$ & Tsavo National Park \\
\hline $\begin{array}{l}\text { Hyalomma } \\
\text { marginatum } \\
\text { rufipes }\end{array}$ & Adult & 7 & $\begin{array}{l}\text { (Loxondota } \\
\text { Africana } \\
\text { Africana) } \\
\text { Elephant }\end{array}$ & Tsavo National Park \\
\hline $\begin{array}{l}\text { Hyalomma } \\
\text { Truncatum }\end{array}$ & Adult & 17 & $\begin{array}{l}\text { (Loxondota } \\
\text { Africana } \\
\text { Africana) } \\
\text { Elephant }\end{array}$ & Tsavo National Park \\
\hline $\begin{array}{l}\text { Hyalomma } \\
\text { Dromedarii }\end{array}$ & Adult & 3 & $\begin{array}{l}\text { (Loxondota } \\
\text { Africana } \\
\text { Africana) } \\
\text { Elephant }\end{array}$ & $\begin{array}{l}\text { (Loxondota } \\
\text { Africana } \\
\text { Africana) } \\
\text { Elephant }\end{array}$ \\
\hline $\begin{array}{l}\text { Hyalomma } \\
\text { Albiparmatum }\end{array}$ & Adult & 5 & $\begin{array}{l}\text { (Diceros } \\
\text { bicorrnis) Rhinoceros }\end{array}$ & Tsavo National Park \\
\hline $\begin{array}{l}\text { Dermacentor } \\
\text { rhinocerinus }\end{array}$ & Adult & 3 & L. Nakuru National Park \\
\hline
\end{tabular}

Table 1: Number of tick species that were correctly identified morphologically from diverse animal species by genus from Lake Nakuru and Tsavo National Parks. Four genera were correctly identified namely Amblyomma, Hyalomma, Rhipicephalus and Dermacentor.

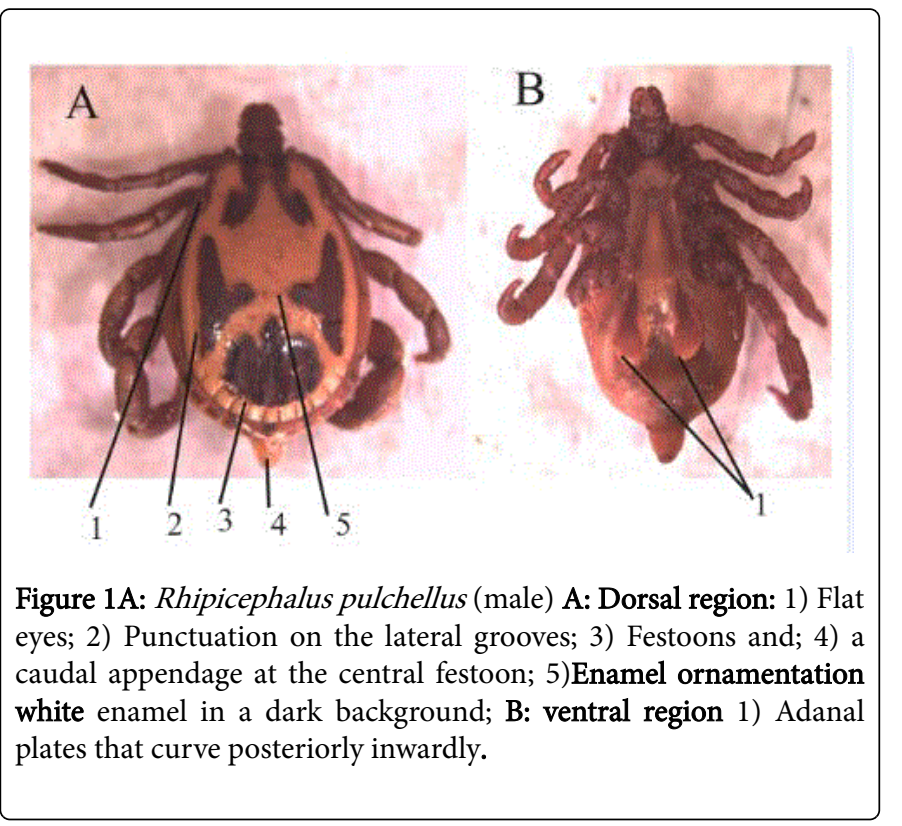

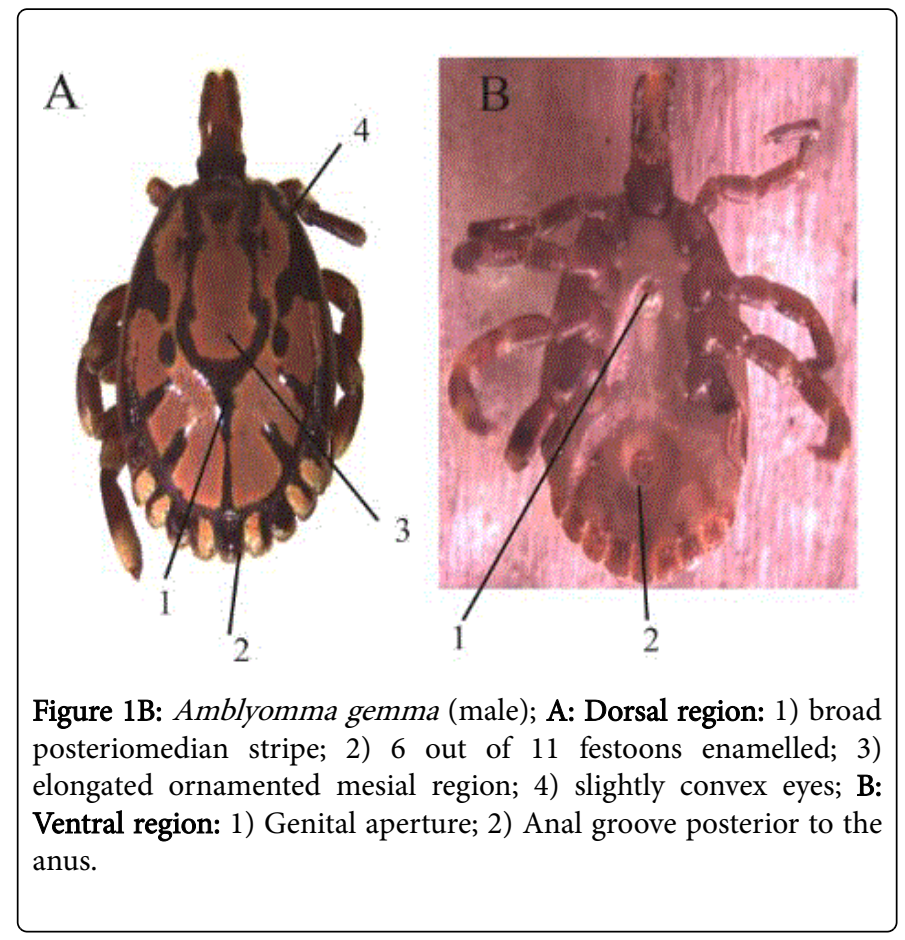


Citation: Muruthi CW, Lwande OW, Makumi JN, Runo S, Otiende M, et al. (2016) Phenotypic and Genotypic Identification of Ticks Sampled from Wildlife Species in Selected Conservation Sites of Kenya. J Veterinar Sci Technol 7: 293. doi:10.4172/2157-7579.1000293

Page 4 of 8
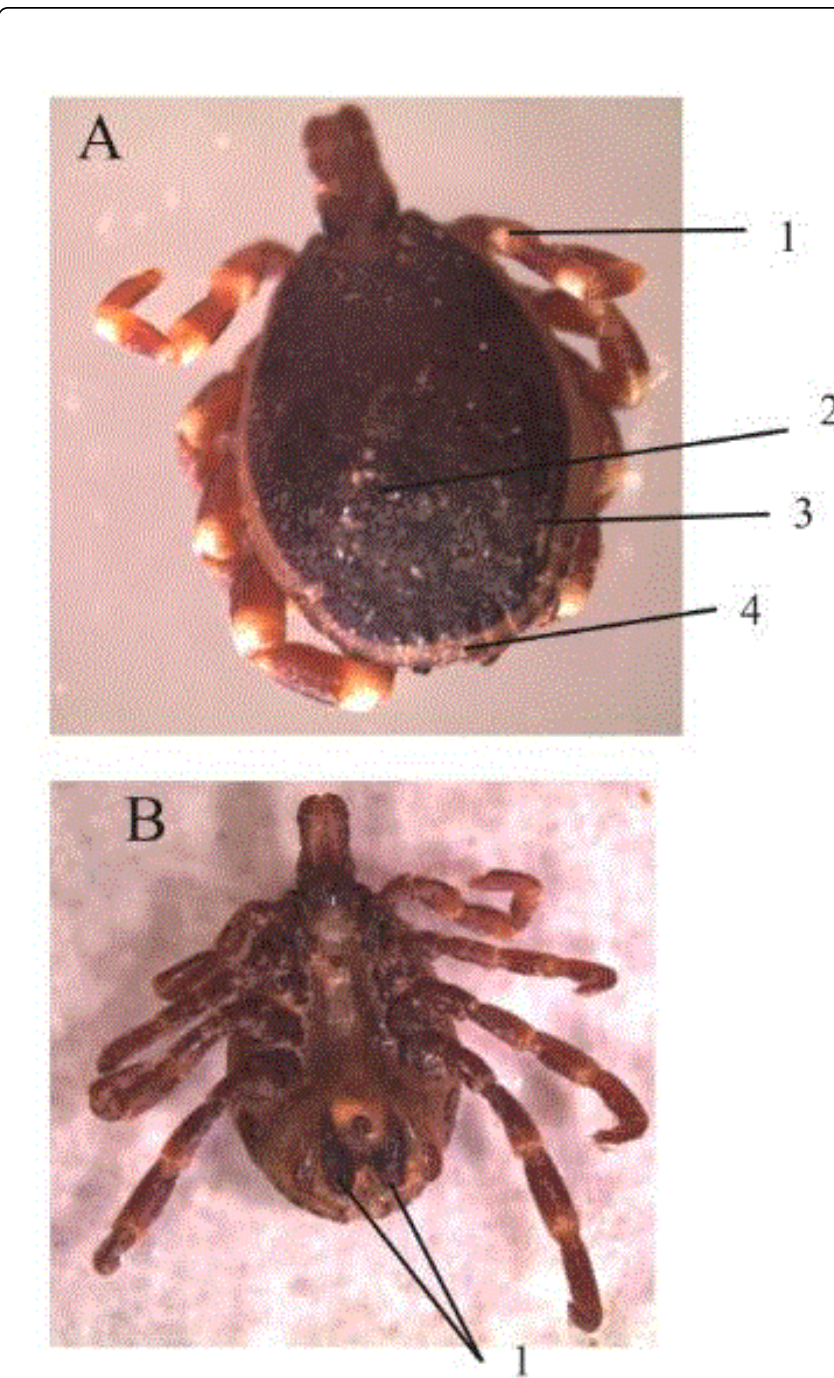

Figure 1C: Hyalomma marginatum rufipes A: Dorsal region 1) Legs with pale rings; 2) scutum rugged large punctuations; 3) short lateral grooves; 4) presence of paracentral festoons; B: Ventral region 1) adanal plates, length twice the width and the distance separating the pates is less compared to the width of their ends.

\section{Genetic Identification}

DNA was isolated from 28 tick samples and after partial amplification of the PCR products, 22 samples were positive and yielded products of approximately $900-1200 \mathrm{bp}$. Different species could be discriminated from the ITS 2 fragment size. The fragment size markers of $R$. pulchellus was estimated at $1100 \mathrm{bp}, A$. variegatum 1200 bp, H. marginatum 1500 bp and H. dromedarii 1200 bp. A comparison of the ITS 2 sequence identified in this study with the sequence deposited in the GenBank registered different homology with different genera. From the data, six samples showed between $98-100 \%$ homology corresponding to $R$. pulchellus sequences obtained from Australia. Another seven samples showed 98\% homology with $A$. variegatum sequences obtained from the U.S.A. Two Samples showed 92\% homology with $H$. dromedarii while sample one showed $91 \%$ homology with ITS 2 sequence of $A$. humerali from Brazil in the
GenBank The study sequences were deposited in the GenBank with the following accession numbers; KM819710 for $R$. pulchellus, KM819712 for $A$. variegatum, KM819713 and KM819711 for $H$. marginatum rufipes and $H$. dromedarii respectively (Table 2 ).

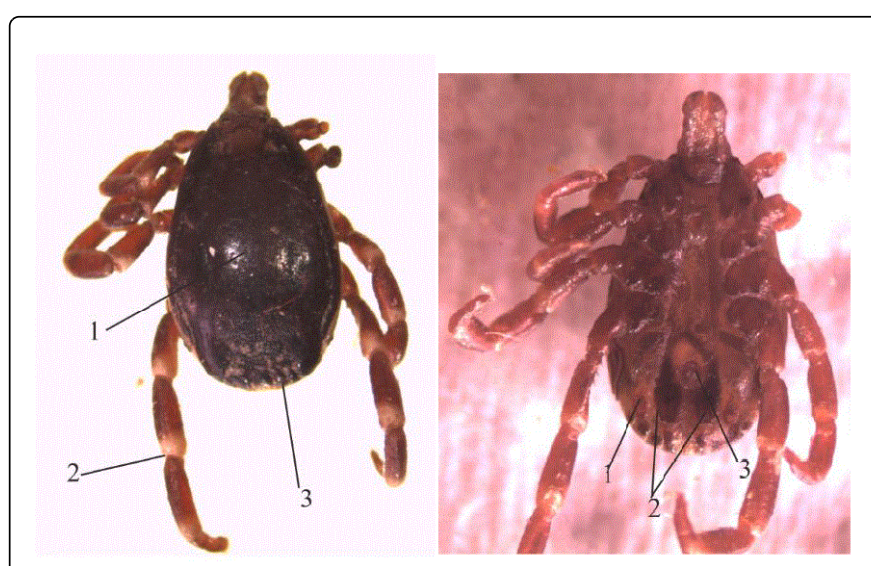

Figure 1D: Hyalomma truncatum (male); Dorsal region 1) Dark and shiny conscutum; 2) Pale rings on the legs; 3) Festoons; and caudal depression; Ventral region 1) Sub-anal plates; 2) Adanal plates with squared-ends; 3 ) Anus.

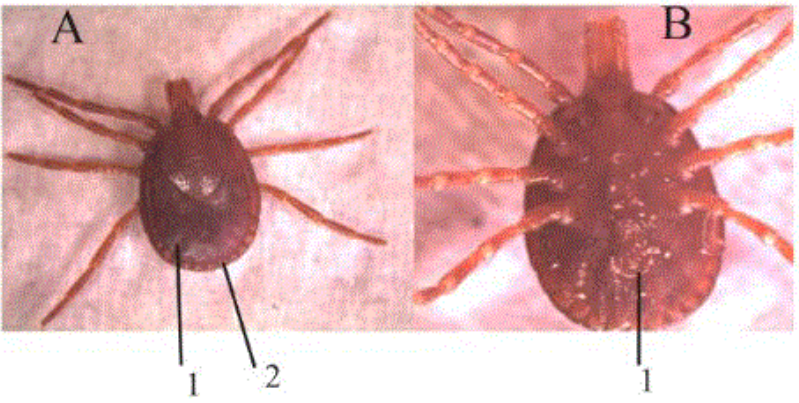

Figure 1E: Amblyomma tholloni (female) A Dorsal region 1) inornate scutum; 2) non-enamelled festoons; B Ventral region 1) Anus.

Sequence from this study and reference sequence obtained from the GenBank were aligned using multiple alignment program Clustal X. Maximum Composite Likelihood method was used in computing the evolutionary distance. Figure 1 shows the Phylogenetic tree generated from partial ITS sequence data. The branch length represents evolutionary changes that have taken place over time and the amount of genetic change is represented by a scale of 0.1 . The number of substitution which is related to the clustering together of the taxa as a bootstrap test, is represented by a percentage value; that is, the number of substitution per 100 nucleotide sites and is shown above the branches. The tree was rooted to the genus Ixodes.

From the figure, $R$. pulchellus and $A$. variegatum haplotypes clustered together at their respective group with a high bootstrap value of $99 \%$. H. marginatum rufipes also clustered together with the reference sequence while sample $39 \mathrm{~s}$ and $40 \mathrm{~s}$ which shared recent ancestor origin with $H$. anatolicum with a bootstrap support of $79 \%$. $H$. dromedarii clustered together with the reference $H$. dromedarii ITS 
Citation: Muruthi CW, Lwande OW, Makumi JN, Runo S, Otiende M, et al. (2016) Phenotypic and Genotypic Identification of Ticks Sampled from Wildlife Species in Selected Conservation Sites of Kenya. J Veterinar Sci Technol 7: 293. doi:10.4172/2157-7579.1000293

Page 5 of 8

2 sequence deposited in the GenBank with a high bootstrap (99\%) humerale with a low bootstrap support of 51\%. Oxidi dammini was while $A$. humerali is clustered together with $A$. tuberculatum than $A$. used as an out group making the tree is a rooted one (Figure 2).

\begin{tabular}{|c|c|c|c|c|c|c|}
\hline Genus & Accession Number & Tick species & ITS fragment Size & $\%$ Identity & Reference sequence & Origin Country \\
\hline \multirow[b]{6}{*}{ Rhipicephalus } & \multirow[b]{6}{*}{ KM819710 } & R.pulchellus & 1100 & 100 & AF271275 & Australia \\
\hline & & R.puchellus & 1100 & 100 & AF271275 & Australia \\
\hline & & R.pulchellus & 1200 & 98 & AF271275 & Australia \\
\hline & & R.pulchellus & 1200 & 98 & AF271275 & Australia \\
\hline & & R.pulchellus & 1100 & 99 & AF271275 & Australia \\
\hline & & R.pulchellus & 1100 & 99 & AF271275 & Australia \\
\hline \multirow[b]{8}{*}{ Amblyomma } & \multirow[b]{8}{*}{ KM819712 } & A.variegatum & 1200 & 98 & HQ856759 & U.S.A \\
\hline & & A.variegatum & 1200 & 98 & HQ856759 & U.S.A \\
\hline & & A.variegatum & 1200 & 98 & HQ856759 & U.S.A \\
\hline & & A.variegatum & 1200 & 98 & HQ856759 & U.S.A \\
\hline & & A.variegatum & 1200 & 97 & HQ856759 & U.S.A \\
\hline & & A.variegatum & 1200 & 98 & HQ856759 & U.S.A \\
\hline & & A.variegatum & 1200 & 98 & HQ856759 & U.S.A \\
\hline & & A.humerali & 800 & 91 & AY887111 & Brazil \\
\hline \multirow[b]{13}{*}{ Hyalomma } & \multirow[b]{11}{*}{ KM819713 } & H. marginatum & 1500 & 95 & JQ737104 & China \\
\hline & & rufipes & & & & \\
\hline & & H. marginatum & 1500 & 95 & JQ737104 & China \\
\hline & & rufipes & & & & \\
\hline & & H. marginatum & 1500 & 95 & JQ737104 & China \\
\hline & & rufipes & & & & \\
\hline & & H. marginatum & 1500 & 95 & JQ737104 & China \\
\hline & & rufipes & & & & \\
\hline & & H. marginatum & 1600 & 95 & JQ737104 & China \\
\hline & & rufipes & & & & \\
\hline & & H. marginatum rufipes & 1600 & 95 & JQ737104 & China \\
\hline & \multirow[b]{2}{*}{ KM819711 } & H.dromedarii & 1200 & 95 & JQ733570 & India \\
\hline & & H.dromedarii & 1200 & 92 & JQ733570 & India \\
\hline
\end{tabular}

Table 2: Identity of tick species and their bp sizes, and percentage similarity value with the references sequences.

\section{Morphological and molecular characterization of tick samples}

Diverse ticks were identified using each technique were compared. The number of $R$. pulchellus, $A$. variegatum and $\mathrm{H}$. dromedarii identified both morphologically and genetically were the same; that is, 6, 7 and 2 respectively. Under the genus Hyalomma 4 species were identified H. marginatum rufipes morphologically and 6 genetically. Two ticks were first identified as $\mathrm{H}$. marginatum rufipes based on morphology but then by genotyping and comparison with reference sequences they were reclassified as $\mathrm{H}$. truncatum and $\mathrm{H}$. albiparmatum. Similarly, one tick was morphologically identified as D. rhinocerinus but by genotyping the tick was reclassified as A. humerali (Table 3). Congruency between morphological and genetic traits was high as depicted by correlation co-efficient of $0.941(\mathrm{P}=0.01)$. 

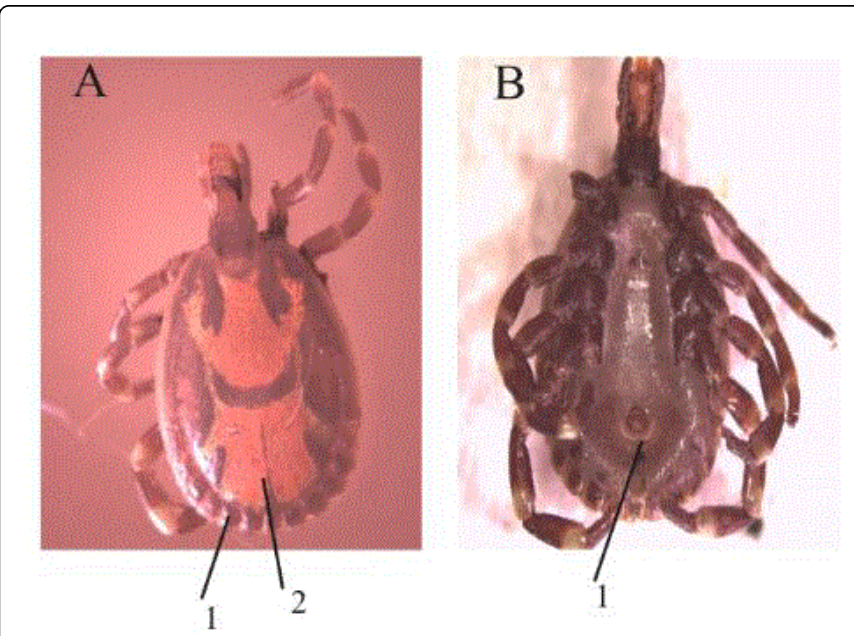

Figure 1F: Amblyomma variegatum (male) A dorsal region 1) nonenamelled festoons; 2) narrow posteriomedian stripe; B ventral region 1) Anus.

\begin{tabular}{|l|l|l|}
\hline Species & $\begin{array}{l}\text { No. identified } \\
\text { Morphologically }\end{array}$ & $\begin{array}{l}\text { No. identified } \\
\text { genetically }\end{array}$ \\
\hline R. pulchellus & 6 & 6 \\
\hline H.marginatum rufipes & 4 & 6 \\
\hline H.truncatum & 1 & 0 \\
\hline H.dromedarii & 2 & 2 \\
\hline H. albiparmatum & 1 & 0 \\
\hline A. variegatum & 7 & 7 \\
\hline A. humerali & 0 & 1 \\
\hline D. rhinocerinus & 1 & 0 \\
\hline
\end{tabular}

Table 3: Number of tick samples identified using phenotypic and phylogenetic techniques.

\section{Discussion}

Various tick genera are associated with various diseases, for example Amblyomma species are associated with viruses noted to be mosquitoborne. More importantly, the impact of ticks on human health is on the rise and more novel microbial associations have continued to be described [10]. There is need therefore, for accurate identification of ticks in order to develop better control measures.

In this study, ticks collected from wild herbivores in L. Nakuru and Tsavo National Park was identified both morphologically and genetically. Morphologically, Amblyomma species and $R$. pulchellus were easily identified using Walker's identification keys. Male $R$. pulchellus were easily identified by their unique striped enamel on a brown-dark background over their conscutum as described by Beati \& Keirans who observed that male $R$. pulchellus have characters that are useful for classification and easily distinguished [11]. Female $R$. pulchellus were easily identified by their association with the males and through their fine and sparse large punctuation on the scutum and
U-shaped genital aperture. Amblyomma species were identified by ornamentation, long mouths and festoons in line with Piazark [12].

It was difficult to differentiate some Male $H$. truncatum from male $H$. marginatum rufipes. The distinctive features that differentiate the two species, the caudal depression present on $H$. truncatum and absent in $\mathrm{H}$. marginatum rufipes; and dense even punctuation on $H$. marginatum rufipes. However, some species identified as $H$. truncatum had morphology of $H$. marginatum; that is, despite the presence of caudal depression, some species identified as $H$. truncatum had dense even covering of punctuations on their conscutum, a feature of $H$. marginatum rufipes. As such, it was difficult using Walker's identification to distinguish between $H$. truncatum and $H$. marginatum rufipes, though the offspring were regarded as $H$. truncatum. These observations are similar to other studies which have reported difficulties in identifying Hyalomma species using nomenclatures [7]. This is attributed to natural hybridization in the genus Hyalomma [13]. The authors reported that initial hybridization between $H$. marginatum rufipes and $H$. truncatum resulted in a hybrid with more morphological characteristic of $H$. truncatum. Similar observations were made by Hadani \& Cwilich who noted that hybridization of $H$. excavatum and $H$. marginatum resulted to male offpsprings with morphological characterization of both $H$. margiatum and $H$. excavatum [14]. In this study, difficulties observed in differentiating Hyalomma species may also be attributed to such natural hybridization between the two species in the wild.

Other tick samples could not be identified due to lost body parts and physical damages. For example, in the genus Amblyomma, some tick samples had partially lost the conscutum tampering with the ornamentation, making it difficult to identify a problem observed by Abdigoudarzi et al. who noted that morphological changes that occur on ticks' surface body may result to misleading identification [7].

Recent molecular work on tick species has used the ITS 2 as a marker in identifying ticks especially in differentiating closely related genus [15-17]. Amplification of the entire ITS 2 have been done by various researchers and mixed results were observed including Zahler et al. and Murell et al. who attributed the unsatisfactory to specific nature of the ITS 2 region in ticks and some repeated fragments in the region $[18,19]$.

In this study, partial sequence of the ITS 2 region was used to identify tick samples and different genera were differentiated based on the fragment sizes. The Rhipicephalus species was estimated at $1100 \mathrm{bp}$ and Amblyomma species, 1200 and Hyalomma species, at $1500 \mathrm{bp}$. The results are similar to findings by Abdigourdarzi et al. who reported similar sizes for the three genera [7].

Sampled ticks were compared and identified with the sequences from the GenBank, and $R$. pulchellus and A. variegatum had a percentage similarity ranging between $98-100 \%$. This suggested that both species could be regarded according to the genotypic identification given that in the phylogenetic tree, both species fell in their respective monophyletic group, clustering together, with a high bootstrap of $99 \%$. The low percentage similarity value (92-95\%) shown by Hyalomma species to the corresponding accession sequences in the GenBank could be due to diverse evolution as a result of geographical separations [20].The difference could be attributed to single nucleotide substitution between both sequences due to individual variation as a result of their wide range of distribution; an observation that is in agreement with other studies which showed that sequence divergence may be due to phylogeographical units in a given species [21]. 
Citation: Muruthi CW, Lwande OW, Makumi JN, Runo S, Otiende M, et al. (2016) Phenotypic and Genotypic Identification of Ticks Sampled from Wildlife Species in Selected Conservation Sites of Kenya. J Veterinar Sci Technol 7: 293. doi:10.4172/2157-7579.1000293

Page 7 of 8

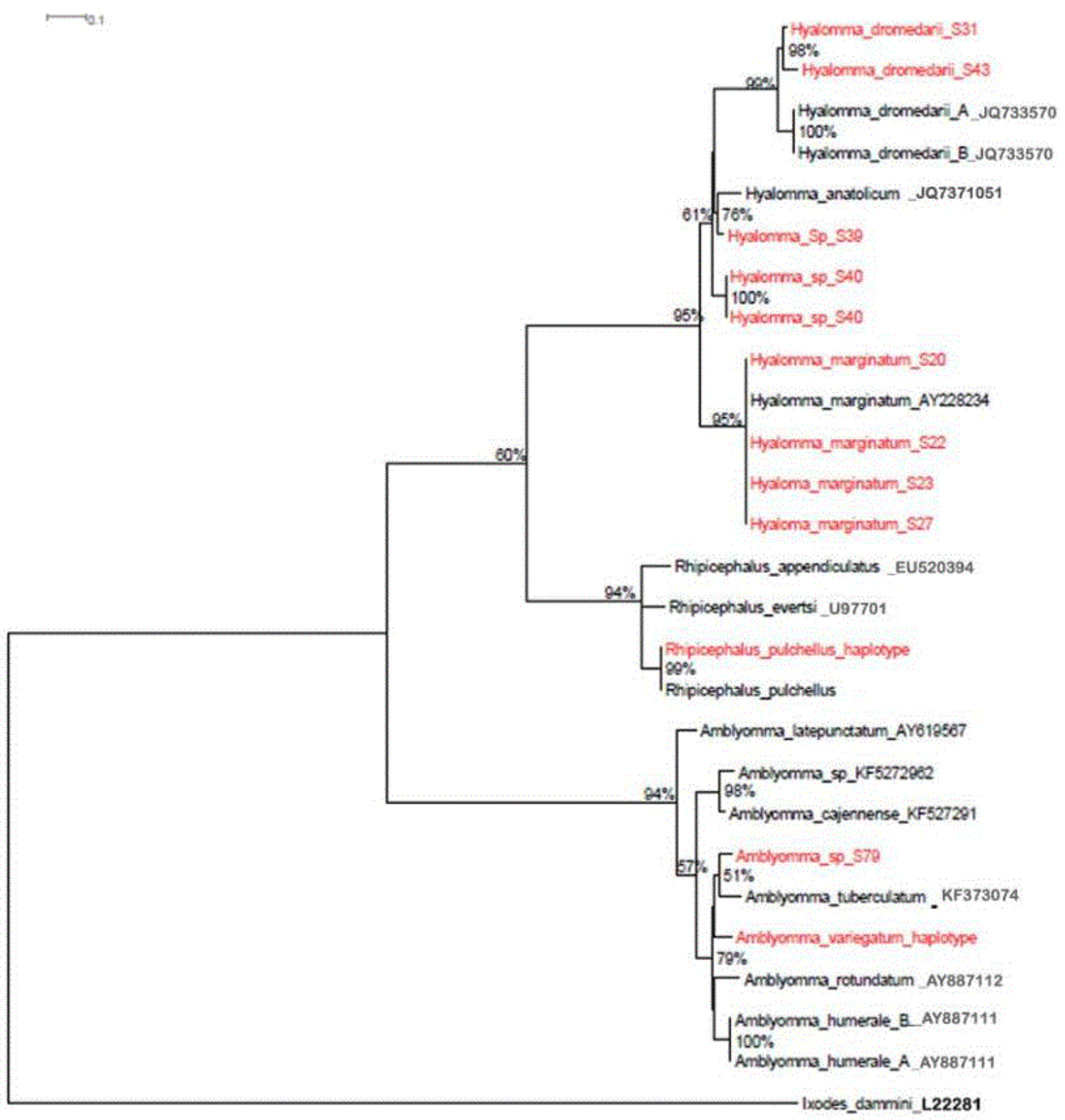

Figure 2: Sequence from the study and reference sequence obtained from the GenBank aligned using multiple alignment programs Clustal X. Evolutionary distance computed using the Maximum Composite Likelihood. The amount of genetic change is represented by a scale of 0.1 . The number of substitution is represented by a percentage value; that is the number of substitution per 100 nucleotide sites and is shown above the branches. The reference sequences are in bold. The tree was rooted to the genus Ixodes.

This was also noted in $H$. dromedarii, with a low similarity value (92\%) while the study sequence clustered together with the reference sequence with a high bootstrap of $99 \%$. Such similarity value could be associated with the cryptic hybridization factor which according to Rees et al. results to nucleotide substitution [13]. Two samples considered $H$. marginatum rufipes failed to cluster together with the rest of the species in the phylogenetic tree. Phenotypically, the tick samples were identified as $H$. truncatum and $H$. albiparmatum; and therefore, the high dissimilarity value and failure to cluster together with the rest of $H$. marginatum rufipes could be attributed to lack of corresponding sequences in the GenBank. This could also be the case in $A$. humerale which had been identified as $\mathrm{D}$. rhinocerinus phenotypically. 
Citation: Muruthi CW, Lwande OW, Makumi JN, Runo S, Otiende M, et al. (2016) Phenotypic and Genotypic Identification of Ticks Sampled from Wildlife Species in Selected Conservation Sites of Kenya. J Veterinar Sci Technol 7: 293. doi:10.4172/2157-7579.1000293

Page 8 of 8

In this study, congruency between morphology and genetic traits was high as the correlation coefficient was high at 0.942 . Congruency was observed in Rhipicephalus and Amblyomma species as they had samples matching between morphological and genetical traits. Similar findings have been reported by Lu et al. who observed consistency in their morphological and molecular characteristic of identifying tick species in Japan [22]. Inconsistency was observed in genus Hyalomma and this could be attributed to lack of or few corresponding sequences deposited in the GenBank. It could also have been contributed by several nucleotides mismatches and insertion which could be as a result of geographical separation and hybridization among the species.

\section{Conclusions}

From the findings of the study, genus Rhipicephalus and Amblyomma were easily identified using morphologically characteristics while some $H$. marginatum rufipes and $H$. truncatum could not be easily identified morphologically. Partial amplification of ITS 2 was successful in differentiating tick species in Kenya. Further studies should be done on a wide collection of Ixodidae from Kenya to contribute to the existing ITS nucleotide database in order to have sufficient genetic database to cover tick species.

\section{Competing Interests}

The authors declare that they have no competing interests.

\section{Author Contributions}

Vincent Obanda, Carolyn Wanjira Muruthi, Moses Otiende, J.N.Makumi conceived and designed experiments. Carolyn Wanjira Muruthi, Vincent Obanda, Moses Otiende, Olivia Wesula Lwande, Steven Runo conducted the experimental work. Carolyn Wanjira Muruthi, Vincent Obanda, Moses Otiende, Olivia Wesula Lwande analyzed the data. Carolyn Wanjira Muruthi, Vincent Obanda, Moses Otiende, J.N. Makumi, Olivia Wesula Lwande, Steven Runo contributed to the manuscript. All authors approved the final version for submission.

\section{Acknowledgements}

The project was supported financially by the Kenya Wildlife Services. We acknowledge Samuel Mutura (Institute of Primate Research Kenya) and the KWS Forensic and Genetics laboratory staff including Anthony Businei, Sam Muthemba and Asenath Omondi and Elsie Maina. The authors wish to acknowledge the late Joseph Njuguna Makumi.

\section{References}

1. Jongejan F, Uilenberg G (2004) The global importance of ticks. Parasitology129: S3-S14.

2. Horak I, Vos V De, Brown MR (1983) Parasites of domestic and wild animals in South Africa. Helminth and arthropod parasites of blue and black wildebeest (Connochaetes taurinus and Connochaetes gnou). Onderstepoort Journal of Veterinary Research 50: 243-255.

3. Lanfranchi P, Ferroglio E, Poglayen G, Guberti V (2003) Wildlife veterinarian, conservation and public health. Vet Res Commun 27 Suppl 1: 567-574.
4. Bengis RG, Leighton FA, Fischer JR, Artois M, Mörner T, et al. (2004) The role of wildlife in emerging and re-emerging zoonoses. Rev Sci Tech 23: 497-511.

5. Tonetti N, Berggoetz M, Rühle C, Pretorius AM, Gern L (2009) Ticks and tick-borne pathogens from wildlife in the Free State Province, South Africa. J Wildl Dis 45: 437-446.

6. Peter TF, Anderson EC, Burridge MJ, Mahan SM (1998) Demonstration of a carrier state for Cowdria ruminantium in wild ruminants from Africa. J Wildl Dis 34: 567-575.

7. Abdigoudarzi M (2011) rDNA-ITS2 Identification of Hyalomma, Rhipicephalus, Dermacentor and Boophilus spp.(Acari: Ixodidae) collected from different geographical regions of Iran.

8. Walker AR (2003) Ticks of domestic animals in Africa: a guide to identification of species. Bioscience reports Edinburgh.

9. Lwande OW (2003) Isolation of tick and mosquito-borne arboviruses from ticks sampled from livestock and wild animal hosts in Ijara District, Kenya. Vector-Borne and Zoonotic Diseases 13: 637-642.

10. Jasinskas A, Zhong J, Barbour AG (2007) Highly prevalent Coxiella sp. bacterium in the tick vector Amblyomma americanum. Applied and environmental microbiology 73: 334-336.

11. Beati L, Keirans JE (2009) Analysis of the systematic relationships among ticks of the genera Rhipicephalus and Boophilus (Acari: Ixodidae) based on mitochondrial $12 \mathrm{~S}$ ribosomal DNA gene sequences and morphological characters. J Parasitol 87: 32-48.

12. Piazak N (2005) The First Report of Amblyomma lepidum (Donitz, 1909) in IRAN. Iranian Journal of Public Health 34: 70-73.

13. Rees DJ, Dioli M, Kirkendall LR (2003) Molecules and morphology: evidence for cryptic hybridization in African Hyalomma (Acari: Ixodidae). Molecular phylogenetics and evolution 27:131-142.

14. Cwilich R, Hadani A (1963) Inter-specific hybridization of ticks of the genus Hyalomma. Acta Trop 20: 178-180.

15. Hillis DM, Dixon MT (1991) Ribosomal DNA: molecular evolution and phylogenetic inference. Q Rev Biol 66: 411-453.

16. Rumer L (2011) Differentiation of medically important Euro-Asian tick species Ixodes ricinus, Ixodes persulcatus, Ixodes hexagonus, and Dermacentor reticulatus by polymerase chain reaction. Vector-Borne and Zoonotic Diseases 11: 899-905.

17. Lv J, Wu S, Zhang Y, Chen Y, Feng C, et al. (2014) Assessment of four DNA fragments (COI, 16S rDNA, ITS2, 12S rDNA) for species identification of the Ixodida (Acari: Ixodida). Parasit Vectors 7: 93.

18. Zahler M, Gothe R, Rinder H (1995) Genetic evidence against a morphologically suggestive conspecificity of Dermacentor reticulatus and D. marginatus (Acari: Ixodidae). International journal for parasitology 25: 1413-1419.

19. Murrell AN, Campbell, S. Barker (2001) Recurrent gains and losses of large (84-109 bp) repeats in the rDNA internal transcribed spacer 2 (ITS2) of rhipicephaline ticks. Insect molecular biology 10: 587-596.

20. Taberlet P, Meyer A, Bouvet J (1992) Unusual mitochondrial DNA polymorphism in two local populations of blue tit Parus caeruleus. Mol Ecol 1:27-36.

21. Avise JC, Walker D (1999) Species realities and numbers in sexual vertebrates: perspectives from an asexually transmitted genome. Proceedings of the National Academy of Sciences 96: 992-995.

22. Lu X, Lin XD, Wang JB, Qin XC, Tian JH, et al. (2013) Molecular survey of hard ticks in endemic areas of tick-borne diseases in China. Ticks Tick Borne Dis 4: 288-296. 